\title{
Correction to: The Firearm Safety Among Children and Teens (FACTS) Consortium: defining the current state of the science on pediatric firearm injury prevention
}

\author{
Rebecca M. Cunningham ${ }^{1,2,3} \cdot$ Patrick M. Carter ${ }^{1,2,3}$ - Marc A. Zimmerman ${ }^{2,3}$
}

Published online: August 24, 2019

(C) Springer Science+Business Media, LLC, part of Springer Nature 2019

\section{Correction to:}

J Behav Med (2019) 42:702-705

https://doi.org/10.1007/s10865-019-00077-6

The original version of the article unfortunately contained a typo in the last author name. The author name was incorrectly listed as Mark Zimmerman.

The correct name should be Marc A. Zimmerman.

The original article can be found online at https://

doi.org/10.1007/s10865-019-00077-6.

Rebecca M. Cunningham

stroh@med.umich.edu

1 Department of Emergency Medicine, University of Michigan School of Medicine, 1500 East Medical Center Drive, Ann Arbor, MI 48109, USA

2 School of Public Health, University of Michigan, 1415 Washington Heights, Ann Arbor, MI 48109, USA

3 FACTS Consortium, 2800 Plymouth Rd., Bldg 10-G080, Ann Arbor, MI 48109, USA 